\title{
Selfing the Home: Quest for Indigenous Entity, Metaphors of the Self and the Other in A. K. Ramanujan's Poetry
}

\author{
Kankana Bhowmick \\ Bongaigaon College, Assam
}

\begin{abstract}
This paper intends to analyze the celebrated poems of A. K. Ramanujan in the light of the figurative approach taken by the poet to represent the Self and the Other from a multidimensional point of view. The poems are skillful observations and perceptions of Indian milieu by him as an Indian expatriate in America. His poems bear the idea that physical separation from his motherland with its precious familial, cultural and traditional values kept him tied to his indigenous roots. His unforgettable poems throw light on his beliefs and philosophies which were influenced by the native air that brought to him all ideologies, morals, myths, legends and even superstitions. Regarded as works of unequal genius, the poems reverberate in the minds of the readers. To be brief, the achieved sense of the Other as an expatriate and the inborn identity of the Self deeply rooted in the soil of his motherland inspire the poet to form refined expressions and a poetic vision which generate the idea how self and society can be related to each other through the networks of home and family.
\end{abstract}

Keywords: Self-Other, Expatriate, Myths, Alienation, National allegory, Collective unconscious, Archetypes

The poems of A. K. Ramanujan identify him as a distinguished Indian English poet in whom the inevitable bond with the motherland, legacy to the home and family, its culture are intermingled to inspire the fusion of philosophical and ethical values of his native culture and the detached outlook of Western thoughts. His poetry is born out of the dialectical interplay between his experience both in America and India on the one hand, and that between his sense of own self and its vitality on the other. As a citizen confronting an alien culture when working and living in U.S, he had imbibed many of its attributes as well. He was exposed to a lifestyle which was urbane, to a mindset which was liberal and to a culture which was not only alien but radical and unconventional unlike its traditional Indian counterpart. The tenets of diverse cultures enabled Ramanujan to rise above and appreciate each. As he looks back staying away from his own land, he remembers and shares personal experiences of family life and home. Most of his poems published in the volumes "The Striders" (1966), "Relations" (1971) and "Second Sight" (1986) echo the sense of belongingness as he reminisces his experience with family as a metaphor for the varied but influential ties between past, present and future.

Ramanujan was drawn to the home, and the family it consists of, as he strongly believed in the family that helps a person to imbibe values and culture. The bond of love and familial ties, as portrayed in his poems, do not merely reveal his inner self through a nostalgic journey down memory lane carrying an awareness of the typical Indian family with its huge web of relationships but also bring a sense of alienation. This realization makes him to turn back to his childhood experiences, relate anecdotes and consequently it becomes a source of continuity with an older idea. 
The reality of being away pulls him back to the present from where his view of the distant past becomes more vivid, more transparent relating to the values like morality, religion and ethics taught in the premises of a Hindu Brahmin family. The poem "Extended Family" in "Second Sight" expresses how the poet can stretch his lineage backward to grandfather and forward to no specific point in future. His identification of the self includes not merely the family past and timeless memory that offers an insight backward in time or into an origin that has no appropriate moment of beginning, but at the same time, it engages a speculation of an unknown future, awaiting unmoulded in its time. Like his unborn grandson, he says, he looks up at himself. The poet's idea of family and the rooted self in it derive from the conception of a vastly extended and nebulously curled web that he enjoins on an indefinite, indefinable time stretch. His quest for the Self submerged in the traditional and cultural values rousing from Indian legacy helps him in purging the uncanny feeling of alienation that gives him the transcended entity as the Other.

Ramanujan's "Hindoo Poems" are remarkable representations to study how the poet deals with the themes of Hindu culture. His three renown Hindu poems: "The Hindoo: He reads his GITA and is calm at all events", "The Hindoo: he doesn't Hurt a Fly or a Spider either" and "The HINDOO: the only risk" are the reflections of his Hindu consciousness. The impossible ideal of accepting both good and evil, joy and sorrow in an equal spirit is well expressed in the poem "The Hindoo: He reads his GITA and is calm at all events". In this poem, the poet's attitude is not to satirize Hinduism or the sacred scriptures but rather those Hindus who know the content of the scriptures, as Ramanujan's early domestic culture taught him, but miss its spirit. The religious values he has imbibed through the introduction to the holy scriptures and rituals, stir a rational mind in him rather than a typical orthodox conception of a Hindu Brahmin mindset. He finds his objective correlative in the family and it's religious and traditional practices around him and then shapes his experiences into poems that become neat vignettes on family relationships, transmitted values of religious or traditional practices as well as the well-knitted frame of Indian society. An important fact put to the forth by his poems is the comprehensive knowledge of Indian mythology and folklore. His other self consisting of experiences as an expatriate did not paralyze his native instinct. His native self finds expression when he describes the worship and reverence of the animals including serpents in Indian culture, as they are considered to be the symbol and ornament of lord Shiva. He gives instance in his poem "Snakes" when he says:

Mother givers them milk

in saucers.

The poem evinces a rational attitude of the poet that is able to inculcate practical approach towards his indigenous culture and reveals the irony when the sacred reptile is trampled under the feet of the poet.

The poem, "Small-Scale Reflections on a Great House" in the volume "Relations" encompasses two contradictory states of Hindu joint-family affairs, one being "nothing/ that ever comes into the house/goes out' and the other is 'anything that goes out/ will come back, processed and often/ with long bills attached'. This poem represents an ironic yet celebratory profile of a large Hindu extended family, tracing its history thematically, rather than chronologically, from about the end of the $19^{\text {th }}$ century to the third quarter of the $20^{\text {th }}$ century. The poem is a reflection on the customs, rituals, myths and superstitions that are the part of the family's everyday life; the permutations and combinations in which character-traits are transmitted over several generations; the upbringing of children and the shaping of several kinds of adult lives; the public and private facets of the family in a web of social transactions; the series of minor and major tragedies that strike 
individual members and affect the whole household. The poem also bears the specks of colonial economy of the Raj, and symbolically re-enacts the family's transition from a traditional Indian world to a diversified and distinctly more modern one over the period of a century. It uncovers the understated parallels between the family's fortune and the modern social history of middle class and upper-caste India as a whole, and shapes itself as a national allegory. Family emerges not only as an image of closely clustered relationships or a symbolic tree bearing far spread branches and strongly rooted structure; it develops to a metaphor for memory and 'inscrutable source of life' beyond memory that Ramanujan's concept of the 'self would reveal. The 'great house' is a metaphor of culture too. The individual has validity in relation to the larger culture and this culture is sustained by the tradition and rituals fostered by it. Many of them may appear outdated from the vantage point of the present, people may proclaim them invalid or illegitimate. But, the past cannot be eradicated wholly, for in trying, to get rid of the past, one might get rid of the present as well. "Self-portrait", one of Ramnujan's representative poems in "The Striders", illustrates modern man's concern with the self and provides the matrix within which self becomes relevant:

I resemble everyone
but myself, and sometimes see
in shop windows
despite the well-known laws
of optics
the portrait of a stranger,
date unknown
often signed in a corner
by my father. ('Self-portrait')

It is a poem of life on the changing individual identity. It represents a kind of modern alienation where a man is constantly displaced and falling into oblivion; he cannot resemble his own self from where it originated. Here the time is diluted as the portrait is signed but not dated. Ramanujan's self seems temporary to himself as temporary is his portrait as he 'sometimes see' himself in the shop windows. Critic Gajendra Kumar is of the view that the core of the essential self of the poet persona in the poetry of Ramanujan 'remains as an intuitive world, but this is amended by changed circumstances and decisions. The essential self changes, develops, it grows from the seeds in the past towards a future which while unknowable is already being formed.' So the poet in the poem is neither a nostalgic traditionalist nor an advocate of modernization and westernization. He is a product of both and his poems reflect the personality, conscious of change, enjoying its vitality and contradictions but also aware of the past, the memories which formed his inner self, memories of an unconscious namelessness which are still alive.

'Family' is the central metaphor in the poems of Ramanujan because of the bond that his poems create between past, present and future and for the ways in which all his life is interrelated. Collective memories of the past serve as the source of his poetic inspiration. As Parthasarathy remarks:

In a traditional family the constituent members are lineal descendants as well as collaterals within three, and at times even four degrees of relationship. Economic help refuge in situations of crisis, the upbringing of children are form of the benefit offered by joint family. The family is for Ramanujan, one of the central metaphor with which he thinks.

Ramanujan's family poems are considered to be the source of clarifying his alleged alienation. In the poem "Obituary", he projects himself as one rejecting Hindu rituals, as a detached outsider of his 
cultural ethos. However, a detached son has not reflected ironically on the state of a changed mother, though he has technically succeeded in avoiding the heaviness of his own heart and finally accepting one more ritual to perform annually. He cannot explain or take into account, the state of a changed mother in his ironic strides. The poet's process of distancing himself from a past related to his father's cremation ceremony is paradoxically converted into the ironic representation of powerful feelings by the extreme understatement of personal emotions and by our awareness that wit and ironies are ways for displacing and controlling emotion.

The themes of homely environment and familial inter-connections foreshadow Ramanujan's treatment of ideas about contemporary society and the individual identity of the self rooted in it. His social and personal poetry can be interpreted coherently if it is assumed that the human drama which constitutes the central dynamic of the past also serves as the mechanism that keeps the present day world constantly in motion. However, if the social and personal poems are rearranged hypothetically within a series of concentric circles, in which the outermost periphery contains representations of various environments that lie on the edge of the poet's experience, while the innermost periphery brings together poems about the things that are closest to him, the drama comes sharply into focus. If we move inwards from the outer circle, we first encounter Ramanujan's more impersonal social poems which often enact a drama involving nameless character-types whom he perceives or imagines from a distance. In the second circle, we come across more personal poems about the extended family, which contains relations not only like uncles, aunts and cousins, but also dead grandparents and great grandparents as well as unborn grandchildren and great grandchildren all clustered synchronically and diachronically around the poet, his parents and his siblings. In the third circle, nested inside the sprawling extended family, the readers find representations of the ongoing everyday drama of the nuclear family where the main characters are a husband, a wife, a daughter and a son. In the fourth, smaller and more intimate circle located inside the nuclear family, we discover poems about love and marriage, in which the primary play revolves around a man and a woman, a pair of lovers, or a husband and a wife. In the fifth and the smallest circle, which is compressed almost to a point we come face to face with the poet by himself, as the individual who experiences everything, confronts himself more closely and serves as the subjective center which gives all the concentric zones of experience their basic structure and meaning.

The tension generated by the 'inner' and the 'outer' worlds is apparent in Ramanujan's poetry. He belongs to a South Indian Brahmin background in which the appeal of a close-knit set-up with a fine sense of security and affinity is as strong as the repulsion of having the obligation to carry the dead burden of conservative practices and orthodoxies. His uprooted sensibility gives rise to the two different worlds where he finds himself- the one within and the other without. The roundabout projection the self in his most of the poems deliberately leaves its central position, moves to periphery to establish to connection to other points, and comes back to the original position at the center impregnated with the wisdom of self-discovery. This process of self-discovery, however, does not romanticize the 'other' outside the self nor does it romanticize the innermost self. Through this process, as Ramanujan himself considers it, the aura of the 'outer forms' is generated. The self in the poet retains its freedom to transact with other points beyond the self- such as family, society, culture, religion, institution of marriage- without any prejudice or bias. This distinctive endeavour prevents the self to become an enclosed entity. As a result, a number of poems like: 'Snakes and Ladders', 'Chicagozen', 'Highway Strippers' are embedded in his observations of the life in America rather than bearing the typical expression of Indian legacy.

According to C. G. Jung, the existence of a collective unconscious, the racial memory, endeavours to mould the consciousness of the race. This racial memory inherited by all members of 
the human family connects modern man with his primeval roots. The collective unconscious is manifested in the recurrence of certain images, stories, folklores and figures called 'archetypes'. The archetypes are associated with the experiences not only of the individual but also of ancestors, as a result the influence of the past is inherited in the present self. Ramanujan's poetry show how an Indian poet in English can derive strength from going back to his roots of home and family value system. The interminable manifestation of the archetypal 'self' and the achieved alienation of the 'other' result in establishing a globalized identity that ensures its validity in the roots of a larger culture opening its window to stir the generalized interpretation of poems originated from the mindset of an expatriate. The importance of the native sphere as a intervening factor may indicate why family life serves as a primary theme in many of Ramanujan's early poems and as the main metaphor for society even in his later works. The composite structure of the family turns out to be a part of society that can potentially contain the whole, the web of domestic relations and values which can function as the means to map and interpret the true identity of a person irrespective of the flux of time. Ramanujan's credit lies in his effort to keep intact his originality despite being subjected to the onslaught of various influences both Indian and Western. His poems are not his attempts to portray a distancing identity of the 'self' but the instinctive insider that try to put things as they are and he emotionally remains 'a home-bound pilgrim...'. Thus, through his creations, the poet lives in a world that encompasses- inner and outer, the self and the other, making his entity both equally vivid and vital.

\section{References}

Ramanujan, A. K. (1995). The collected poems of A. K. Ramanujan. ed. Vinay Dharwadker. Delhi: OUP.

Shinde, A. Jayprakash. (2001). "Family as a central Metaphor in A.K.Ramanujan's Poetry". Millennium Perspectives on A.K.Ramanujan. ed. Surya Nath Pandey. New Delhi: Atlantic Publication and distributors.

King, Bruce. (1991). Three Indian Poets. New Delhi: OUP. . (1992). Modern Indian Poetry in English. New Delhi: OUP.

Parthasarthy, R. (1976). “How it Strikes a Contemporary: The Poetry of A.K. Ramanujan.”

The Literary Criterion 12.2.3. P. 194.

Sahu, Nandini. (2000). The Post-colonial Space: Writing the Self and the Nation. New Delhi: Atlantic Publishers and Distributors (P) Ltd.

Kumar, Gajendra. (2001). Indian English Literature: A New Perspective. New Delhi: Sarup \& Sons.

Kankana Bhowmick teaches in Bongaigaon College, Assam, India. 